\title{
Breakthroughs in Groundnut Production Communities in Nigeria
}

\subsection{Enriching Lives of Women: Groundnut Production and Processing Is a Mine of Wealth for Women in Northern Nigeria}

Ms. Hadja Talatu Idrissa (Fig. 6.1), a community women leader, is the chairperson of the Bunkure women group that is active in groundnut production and oil processing. The group which counts 25 members joined the TL projects' family 4 years ago. They started growing a small seed pack of $5 \mathrm{~kg}$ in their community farmland. "It was the harvest of this seed pack that we revolved and planted in a bigger farm plot in the following year," reported. Hadja.

On 1 ha plot, the Bunkure women harvested a total 25 bags of the improved variety SAMNUT 24 against 13 bags they got from 1 ha plot with the old variety.

In addition, the group made more money out of the haulms of the improved variety SAMNUT 24. "We sold the haulms of the improved variety up to 30000 Naira against 12000 Naira of the local variety," says Idrissa (1USD equals 360 Nigerian Naira during that period). "The improved variety, SAMNUT 24, has higher haulms yield and is much appreciated for animal feeding because of its taste and digestibility which is better," she adds.

In 2017, the Bunkure women group produced about 3.5 tons groundnut. The grain is used for household consumption, while the groundnut haulms are sold and the money was used to start dry season groundnut production in 2018. "We don't sell our grain produced, rather, we keep it and process part of it into oil and many by-products which we further sell. Apart from money made from the processing activities, individual members contribute 200 Naira on a weekly basis for the savings box. A weekly savings of about 5000 Naira is kept into the group's bank account."

The interest from this saving permitted the group to conduct many activities to help the community as a whole, including restoring the community health center and its primary school. "We use part of our savings to clean up the community health centre and pay for basic products to sustain the centre. The hospital is now cleaner than before and offers heal thier working environment to staff and to 


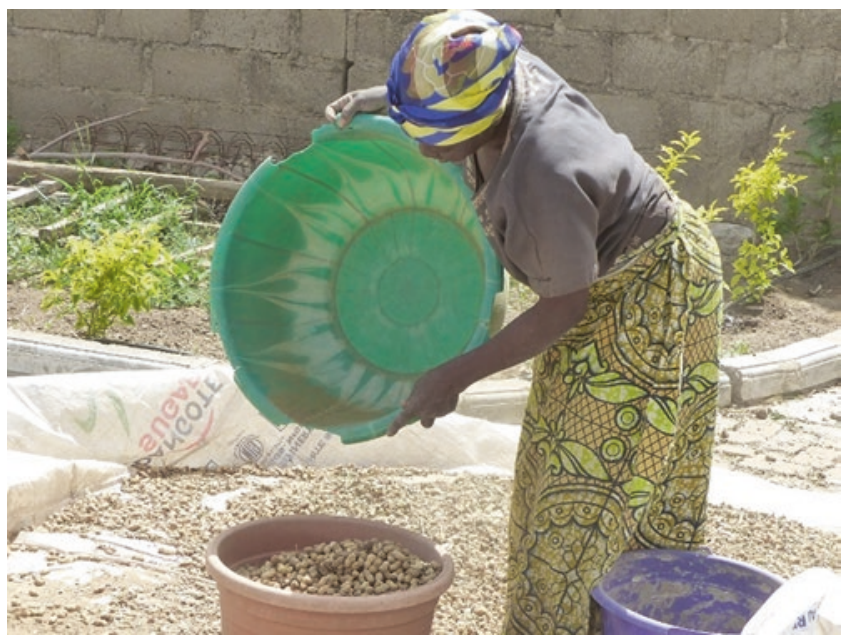

Fig. 6.1 Ms. Hadja Talatu Idrissa, leader of the Bunkure women group, producing groundnut and processing oil, Nigeria (Photo: Diama A)

the patients. Before, people were afraid of visiting the hospital because it was in a bad condition which would expose them to other infections caused by insalubrity of the hospital rather than getting treatment. Also, the compound of the hospital was so weedy, that the nurses could not stay overnight as they were afraid of many animal attacks. Now that we have cleaned up the hospital, they are no longer afraid of staying for long hours in the hospital. As a matter of fact, the health centre now offers 24 hours full services and the nurses are ready to attend the patients at any time, day and night." The women group contributed to repair the beds in the hospital, and this offered a more convenient place for admitted patients including pregnant women. The group also contributed to restoring the doors and windows of the community's primary school.

Ms. Hadja Talatu (Fig. 6.2) says that the group has contributed to improving the education of children within the community of Bunkure. "Before, most of our children used to school up to primary level. Now, we have children at Universities in capital cities." At a more personal level, Ms. Hadja Talatu says she was able to attend the pilgrimage in Mecca, Saudi Arabia, and is proudly happy to say how much progress the women group was able to make from groundnut grain production and processing as well as from groundnut haulms business. "I have a lawyer, a doctor and even an agricultural extension worker."

In a country where women access to land is still a major issue, Ms. Hadja Talatu and many other members of the Bunkure women group are now happy owners of farm lands and many working bulls.

Happiness have different meanings to all and Hadja Talatu (Fig. 6.3) together with the Bunkure women group seems to have reached their goal. Tropical Legumes projects have put a smile on their faces which they have gratefully translated into their community in many ways. The group was recognized in 2015 by the State 


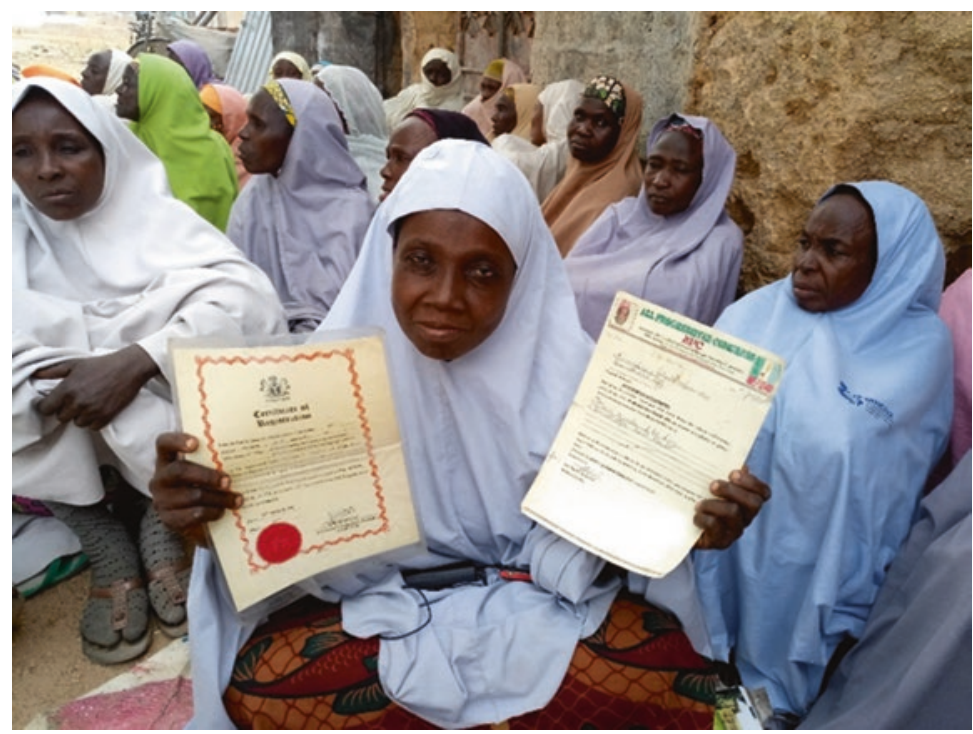

Fig. 6.2 Ms. Hadja Talatu Idrissa showing the legal document of the creation of the Bunkure women group in 2008 and a recognition from the Governor of Kano State for their contribution to the development of the community, Nigeria (Photo: Diama A)

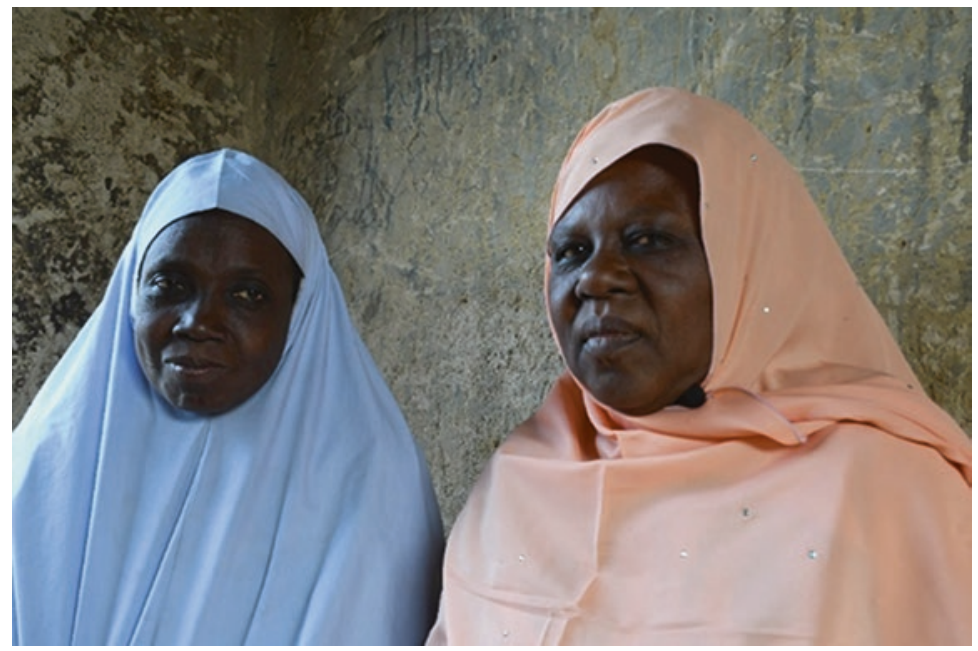

Fig. 6.3 From left to right: Ms. Hadja Talatu Idrissa and Ms. Afsat (Agricultural Extension Agent of the Bunkure Women group, Northern Nigeria) (Photo: Diama A) 
Governor for their substantial contribution to the development of the entire community.

\subsection{Seed Companies Helping to Lift People Out of Poverty: A Breakthrough in Seed Systems with Maina Seeds and Greenspore}

Maina Seeds Ltd. and Greenspore Ltd. are two seed companies based in Kano, Northern Nigeria. Both seed companies have an equal partnership and hence benefit equally from the Tropical Legumes projects, specifically groundnut and cowpea seed production. Tropical Legumes projects (I-II-III) and other various projects have created awareness and raised capacities along the value groundnut and cowpea value chains, including seed companies.

Many farmers were afraid of embracing cowpea production because of the Maruca infestation which caused closer to total loss in the fields and made the farmers poorer, says the late Awalu Balarabe, the Managing Director and Chief Executive Officer of the Maina Seed Limited company (

Fig. 6.4). The project came with technologies for Maruca control along with promised varieties that are higher yielding, relatively resistant to some biotic and abiotic stresses. It introduced improved storage bags for cowpea which helped a long way. Also, extension services were provided by our Agricultural Development Program

Fig. 6.4 Late Awalu Balarabe, the Managing Director and Chief Executive Officer of the Maina Seed Limited Company, Nigeria (Photo: Diama A)

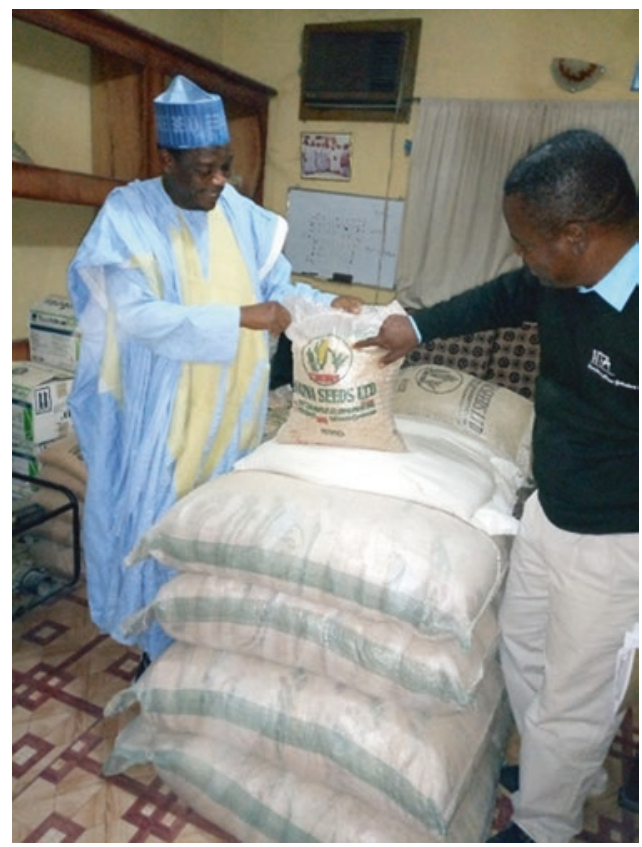


$(A D P)$. In the seed industry, we felt comfortable because we knew that the breeders did not abandon us. We felt comfortable in going into larger production and getting more seed out-growers, he explained.

Improved varieties are now made accessible and sold out to farmers using small seed pack of 1,2, and $5 \mathrm{~kg}$. Another benefit is the improved linkages with more agro-dealers and seed out-growers into the seed value chain and the fact that several farmers attached to the project were linked to seed companies and have become immediate sources of certified seed for seed companies.

Before the projects, farmers were cultivating cowpea and groundnut which were limited to their personal uses. The TL projects came with improved varieties which saved farmers from cropping the same varieties years after years, with poor yield. Farmers were convinced with demonstration plots and accepted new technologies, and by doing so they were able to increase their yields. "It gave reasons to the seed companies to go into mass production of this cowpea. Maina Seeds used to produce less than 2 tons of cowpea per year. Since 2015, before my engagement with the Tropical Legumes projects, I got very low yield, in 2008 for instance I planted $192 \mathrm{~kg}$ of RUDD Red groundnut and only managed to harvest $1600 \mathrm{~kg}$, the yield was very discouraging and that's when I switched to the new varieties of groundnut. We produced up to 30 metrics tons. In years 2016 and 2017 Maina Seeds has seen production reach up to 40 metrics tons of cowpea," adds the late Awalu.

In the same way, new groundnut varieties (SAMNUT 24, SAMNUT 25, and SAMNUT 26) were promoted through demonstration plots and field days were conducted over the years in farmers' fields which they adopted. "For the first time through the project, we have access to breeder seed of improved groundnut varieties," says the late Awalu.

Such support including trainings on seed production techniques of both cowpea and groundnut, quality control including aflatoxin pre- and postharvest management support, were given to seed companies. Other capacity building focused on business skills and seed entrepreneurship "We have also scaled down such trainings to our out-growers,” adds the late Awalu.

Greenspore Agri Limited is a seed company based in Kano State operating in eight states in Nigeria. The company started with groundnut and cowpea seeds at a very low level, because primarily there were no sufficient foundation seeds for these crops and there was need for promotion of these crops. "We are so lucky to have become collaborators in the Tropical Legumes projects II and III," notes Mr. Shehu (Fig. 6.5). "We didn't have enough access to foundation seed, with less breeder seed in stock. More foundation seed and breeder seed became available and gave us an advantage of extrapolating and increasing our production and yield. We have at least 3 new varieties and the farmers have been very happy because most of them are resistant to leaf diseases, including rosette. With regards to cowpea production, greenspore started with a little amount of foundation seed that was available. Now that we have more foundation seed available, we can produce more certified seed."

As the availability of the foundation seed increased, the seed companies were able to promote them among a network of out-growers, thus improving their revenue and capital. A good case study is the Maina Seeds Company which according to 


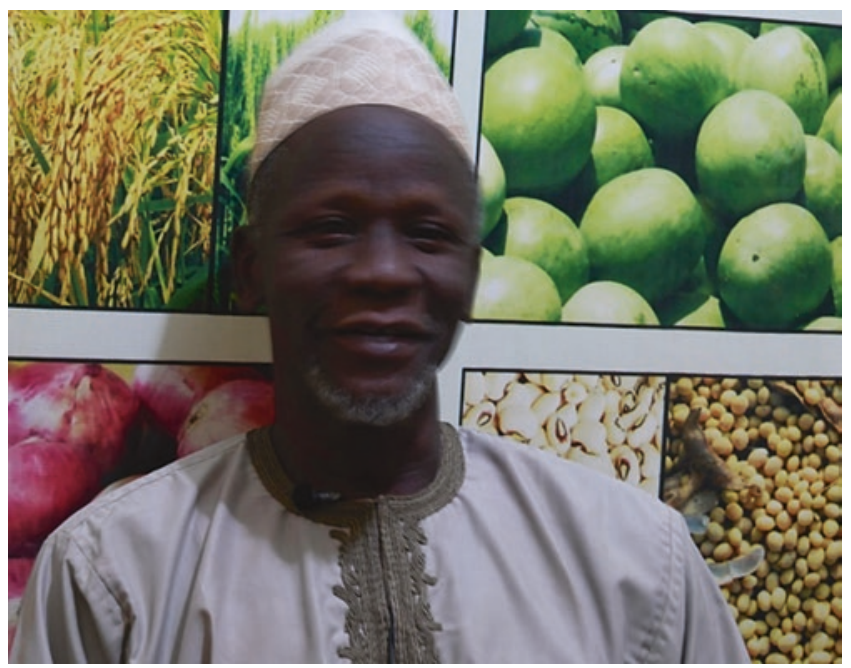

Fig. 6.5 Mr. Balarabe Shehu is the Managing Director and Executive Director of Greenspore Agri Limited, Nigeria (Photo: Diama A)

the Managing Director, the late Awalu Balarabe, the capital increased from 1 million naira to 250 million naira in 2017. "When we started, we had no office to call our own, today we have established a permanent office, a showroom, a shop, an agricultural laboratory, and a conference room. We were using laborers and horses to cultivate our farm; today, by the grace of God, Maina Seeds Company has its own tractors, a combined harvester and threshers. We were enhanced and definitely this project has helped," testifies the late Managing Director of Maina Seeds.

"Our biggest success with Tropical Legumes projects is the introduction of the company to scientists and to extensionists. They have exposed us to many other players with several best practices in the seed industry. The benefits are many and beyond mere finances. We have been enhanced as a company," the late Awalu concludes.

Long ago Nigeria was known for famous groundnut pyramids. The country is also among top producers and consumers of cowpea worldwide. However, the market demand is very high and seed companies are still making great efforts to meet the demand. "Although breeder seed is now available in the system, it is not enough," says the Managing Director of Maina Seeds. "We need more of breeder and foundation seeds." the late Awalu added that despite the company is increasing its production to 30 metrics tons, he is still not able to meet the demand of the market. "With the local demand being high, there is need for a concerted effort to increase the delivery of breeder and foundation seed to the seed companies, so that we will be able to produce more, sell more to farmers and reach out to other states outside our immediate operating states." 
"If seed companies continue to get the right support in getting breeder seed and our scientists get more support to produce more breeder seed and foundation seed, the seed companies will scale it up and farmers will take in large quantities,"-believes the late Awalu.

Efforts are being made to bring the Nigerian groundnut pyramids back and farmers are being encouraged by the new SAMNUT 24, SAMNUT 25, and SAMNUT 26 which are high yielding. Also, millers sprinkled, and the food industry is using the produce to make various snack.

\subsection{New Groundnut Varieties Released by Breeding Program After Decades}

"The improved groundnut varieties SAMNUT 24, SAMNUT 25 and SAMNUT 26 released to farmers between 2012 and 2013 are our proud achievements from Tropical Legumes projects. Three new lines are being nominated to the National Variety Release Committee of Nigeria for registration and release in 2018," says Prof. Candidus Echewku, groundnut breeder, Institute of Agricultural Research, Nigeria.

Open Access This chapter is licensed under the terms of the Creative Commons Attribution 4.0 International License (http://creativecommons.org/licenses/by/4.0/), which permits use, sharing, adaptation, distribution and reproduction in any medium or format, as long as you give appropriate credit to the original author(s) and the source, provide a link to the Creative Commons licence and indicate if changes were made.

The images or other third party material in this chapter are included in the chapter's Creative Commons licence, unless indicated otherwise in a credit line to the material. If material is not included in the chapter's Creative Commons licence and your intended use is not permitted by statutory regulation or exceeds the permitted use, you will need to obtain permission directly from the copyright holder.

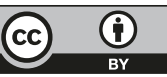

